\title{
DIAGNÓSTICO DA RELAÇÃO DO MUNICÍPIO DE PRESIDENTE PRUDENTE/SP COM O LIXO: UMA ANÁLISE ALÉM DA SITUAÇÃO ATUAL
}

\author{
Mayara Cristina de Paula Felipe ${ }^{1}$, Hudson Matheus Carvalho Santos ${ }^{2}$ \\ ${ }^{1}$ Universidade Estadual Paulista - UNESP, curso de Geografia, Presidente Prudente, SP. ETEC Prof. Dr. Antônio Eufrásio \\ de Toledo, Especialista técnica em Geoprocessamento, Presidente Prudente, SP. ${ }^{2}$ Universidade do Oeste Paulista - \\ UNOESTE, curso de Engenharia Civil, Presidente Prudente, SP. ETEC Prof. Dr. Antônio Eufrásio de Toledo, Especialista

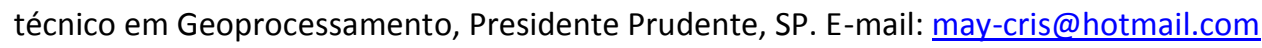

\section{RESUMO}

O presente estudo tem como objetivo analisar a distribuição das antigas áreas de deposição de resíduos sólidos no município de Presidente Prudente, identificando a aproximação desses locais com as APPs (Áreas de Preservação Permanente). Dessa forma, realizou-se um levantamento de dados a partir da revisão bibliográfica e observou-se as dinâmicas atuais desses limites por meio de trabalhos de campo. Verificou-se que a administração dos resíduos sólidos urbanos no município de Presidente Prudente não realizou estudos sobre as escolhas de tais áreas. Constatouse que, os critérios levados em consideração sempre foram os de "tapa buracos", além disso, de esconder dos olhos da população, principalmente a de maior poder aquisitivo, o volume dos resíduos. Conclui-se que, as áreas escolhidas para a deposição dos resíduos eram periféricas e, geralmente, já existia uma população de baixo poder aquisitivo vivendo próximo. Atualmente, o município vive um grande dilema referente à deposição de resíduos, ou ao lixão, pois o mesmo está próximo à zona urbana e a cursos d'água.

Palavras-chave: Resíduos sólidos, Deposição, Lixão, Áreas de Preservação Permanente.

\section{DIAGNOSISTHE REGARDING OF THE MUNICIPALITY PRESIDENTE PRUDENTE/SP WITH WASTE: AN ANALYSIS BEYOND THE CURRENT SITUATION}

\begin{abstract}
This study aimed to analyze the distribution of the oldest areas of disposal of solid waste in the municipality of Presidente Prudente, identifying the approach of these locations with the APPs. Thus, there was a survey of data from the literature review and noted that the current dynamics of these limits through fieldwork. It was found that the administration of municipal solid waste in the municipality of Presidente Prudente did not perform studies on the choices of such areas, the criteria taken into consideration were always the "patch holes", in addition, to hide from the people's eyes, especially the more purchasing power, the volume of waste. In this context, the areas chosen for the deposition were peripheral and generally there was already a population of low income living nearby. Currently, the city is experiencing a major dilemma regarding the dump, because it is close to urban areas and waterways.
\end{abstract}

Keywords: Solid waste, Deposition, Dump, Permanent Preservation Areas. 


\section{INTRODUÇÃO}

A concentração da população nas cidades aumentou a demanda por bens de consumo, de tal modo que, se acentuaram os problemas ambientais, sobretudo, no que tange aos processos de geração de resíduos e a disposição final desses. Segundo Carrion e Kurak (1996), esse cenário teve sua origem nos primórdios da civilização humana, quando o homem deixou o nomadismo para se estabelecer em locais fixos. Assim, na medida em que a população crescia, os problemas ambientais, também, foram se agravando, sendo mais intenso nas cidades maiores e em regiões mais industrializadas.

Smith (1988 apud TAKENAKA, 2008, p.22) afirma que "em uma economia de troca, a apropriação da natureza cada vez mais é regulada por firmas e instituições sociais e, destarte, os seres humanos começam a produzir mais do que o suficiente para sua subsistência", assim nos últimos séculos a geração de resíduos teve um crescimento desenfreado.

Portanto, a questão que se coloca é: "o que fazer com esses resíduos gerados?". Este é um desafio enfrentado por muitos municípios brasileiros, nos quais os resíduos sólidos são dispostos em locais inadequados sem a realização de nenhum tipo de tratamento, ocasionando graves problemas ao meio ambiente e na sociedade.

Nesse contexto, o município de Presidente Prudente, localizado no extremo Oeste Paulista (Figura 1), vive essa problemática, pois o material coletado diariamente é colocado, desde o ano de 1997, em uma área próxima à malha urbana, sem a realização de nenhum tipo de preparo, causando impactos tanto ambientais quanto sociais.

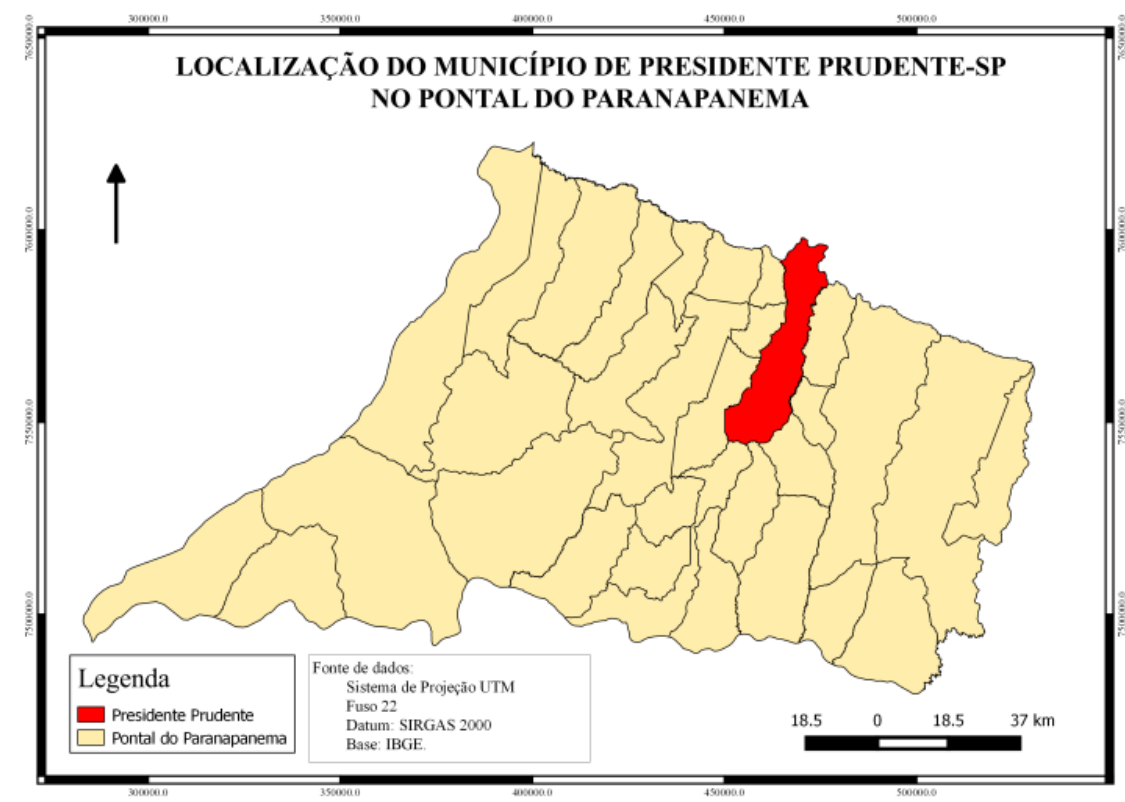

Figura 1. Localização do município de Presidente Prudente- SP.

Org.: Mayara Cristina de Paula Felipe 
Diante desse cenário, viu-se a necessidade de desenvolver o estudo em questão, para constatar os impactos das antigas e atual área de disposição de resíduos sólidos, localizadas sobre diversos pontos da malha urbana do município de Presidente Prudente, procurando analisar principalmente a aproximação desses locais às Áreas de Preservação Permanente (APP).

\section{METODOLOGIA}

Primeiramente, realizou-se uma revisão bibliográfica sobre a temática de estudo. Dessa forma, a partir da bibliografia consultada, identificou-se os antigos locais de deposição dos resíduos sólidos urbanos. Após essa etapa, realizou-se vários trabalhos de campo com o objetivo de verificar as dinâmicas atuais desses locais, procurando observar os seus atuais usos.

Posteriormente, iniciou-se a elaboração dos produtos cartográficos para demonstrar a aproximação das antigas áreas de deposição de resíduos à APPs. Para a elaboração desses mapas, utilizou-se o Sistema de Informação Geográfica (SIG) denominado de QGIS, trata-se de um software livre. Com base nos produtos cartográficos obtidos, na revisão bibliográfica e nos trabalhos de campo, iniciou-se as inter-relações entre essas informações, resultando nas análises geradas nesse trabalho.

\section{RESULTADOS}

Mesmo diante dos avanços no âmbito da tecnologia, o principal destino final dos resíduos sólidos urbanos ainda são os lixões, estes são caracterizados pela disposição dos resíduos a céu aberto, sem nenhuma forma de cobertura, tratamento ou compactação. Desse modo, tornam-se verdadeiros monturos de lixo em decomposição, atraindo diversos tipos de animais peçonhentos, insetos, urubus, entre outros.

Dentre os prejuízos ocasionados por este tipo de depósito destaca-se a poluição do solo, das águas superficiais e subterrâneas pelo chorume e a poluição do ar pelos gases emitidos. No município de Presidente Prudente, esses fatores são potencializados pela proximidade dos lixões à área urbana.

Em Presidente Prudente, as áreas escolhidas para a deposição dos resíduos sólidos urbanos encontram-se em sua maioria na área além-linha, ou seja, na zona leste e norte da cidade. As escolhas dessas áreas seguiram principalmente o critério de "tapa buracos". Assim, utilizando os terrenos pertencentes à prefeitura, os quais possuíam relevo muito acidentado, a destinação final do lixo urbano se dava nos fundos de vale e nas erosões dos mesmos, sem a realização de nenhum 
estudo sobre a declividade do terreno, nível do lençol freático e propriedades dos solos (MAZZINI, 1997).

Além disso, por não haver a separação dos resíduos, a não ser pelos catadores, a vida útil dessas áreas era bem menor, fazendo com que incorporassem cada vez mais novas áreas nessa dinâmica de degradação do meio ambiente. Mazzini (1997, p.24) destaca que esta ação contribuiu “[...] para a poluição e degradação de várias áreas em toda cidade e que, pior que utilizar tais espaços como depósitos de lixo é, o descaso para com estas após encerrados". No período entre 1923 e 2014, foram utilizadas em Presidente Prudente mais de 25 áreas para o depósito de resíduos sólidos urbanos, como pode ser observado no Quadro 1.

Quadro 1. Locais utilizados para a disposição final dos resíduos sólidos urbanos, no município de Presidente Prudente- SP (1923-2008).

\begin{tabular}{|l|l|l|l|}
\hline PERÍODO & \multicolumn{1}{|c|}{ ÁREAS UTILIZADAS } & PERÍODO & \multicolumn{1}{c|}{ ÁREAS UTILIZADAS } \\
\hline 1923 & - Centro & 1983 & - Vila Nova Prudente \\
\hline 1940 & - Centro & 1985 & - Parque Furquim (segunda área) \\
\hline 1955 & - Vila Charlote & 1986 & - Curtume Crepaldi \\
\hline 1969 & - Vila Charlote & 1987 & $\begin{array}{l}\text { - Parque Alexandrina (segunda } \\
\text { área) }\end{array}$ \\
\hline $1970-1972$ & - Jardim Primavera* & 1987 & - Parque Furquim (terceira área) \\
\hline 1973 & - Vila Verinha & 1988 & - Parque Watal Ishibashi \\
\hline $1974-1990$ & - Jardim Santa Filomena* & 1988 & - Humberto Salvador \\
\hline $1975-1980$ & Jardim São Judas* & 1990 & - Jardim Planalto \\
\hline 1976 & - Vila Geni & 1990 & - Vila Brasil \\
\hline 1978 & - Parque Alexandrina (primeira & 1991 & - Parque Furquim (quarta área) \\
\hline 1979 & área) & 1994 & - Vila operária \\
\hline 1981 & - Jardim Duque de Caxias & 1996 & - Jardim Guanabara \\
\hline $1982-1989$ & - Vila Marcondes* & 1997 & - Vila Angélica \\
\hline 1982 & - Parque São Matheus & $\begin{array}{l}1997- \\
2014\end{array}$ & - Distrito Industrial \\
\hline
\end{tabular}

* área utilizada por várias vezes em diferentes períodos

Fonte: Adaptado de Mazzini (1997); Takenaka (2008).

Para avaliar os impactos da deposição dos resíduos sólidos urbanos em áreas de fundo de vale no município de Presidente Prudente, foi necessário analisar as legislações ambientais e urbanas vigentes no período, principalmente o Código Florestal, a Lei Complementar de Parcelamento do solo de Presidente Prudente e a Resolução do Conselho Nacional do Meio Ambiente (CONAMA).

Em relação às APPs, a resolução $\mathrm{n}^{\circ}$ 302, de 20 de março de 2002, do CONAMA (Conselho Nacional do Meio Ambiente) define Áreas de Preservação Permanente: 
(...) como instrumento de relevante interesse ambiental, integram o desenvolvimento sustentável, objetivo das presentes e futuras gerações; a função ambiental das Áreas de Preservação Permanente de preservar os recursos hídricos, a paisagem, a estabilidade geológica, a biodiversidade, o fluxo gênico de fauna e flora, proteger o solo e assegurar o bem estar das populações humanas (CONAMA, no302, 2002).

Para exemplificar o conteúdo do artigo do Código Florestal referente às APPs, fez-se uma tabela síntese (Tabela 1) com a metragem da área de preservação permanente de acordo com a largura do curso d'água.

Tabela 1. Metragem das áreas de preservação permanente.

\begin{tabular}{c|c}
\hline Largura do curso d'água & Largura mínima da APP \\
\hline Até 10 metros & 30 metros \\
\hline Entre 10 e 50 metros & 50 metros \\
\hline Entre 50 e 200 metros & 100 metros \\
\hline Entre 200 e 600 metros & 200 metros \\
\hline Superior a 600 metros & 500 metros \\
\hline Nascentes & 50 m no entorno da nascente \\
\hline
\end{tabular}

Fonte: BRASIL, Código Florestal, Lei no. 12.727.

Portanto, a partir dessa base teórica delimitou-se as Áreas de Preservação Permanente no QGIS, utilizando a ferramenta denominada Buffer. Como os cursos d'água analisados não ultrapassam 10 metros de largura, foram delimitadas as APPs de 30 metros para cada margem, e nas áreas de nascentes as APPs foram delimitadas com 50 metros.

Observou-se que grande parte das antigas áreas de deposição de resíduos sólidos urbanos localizava-se em áreas de APP, ocasionando graves problemas ambientais, sobretudo, nos cursos d'água, como exemplo tem-se a Figura 2 referente às antigas áreas de deposição de resíduos sólidos na Vila Verinha (1973), Jardim Santa Filomena (1974 e 1990); Vila Marcondes (1982 e 1989) e Vila Brasil (1990). 


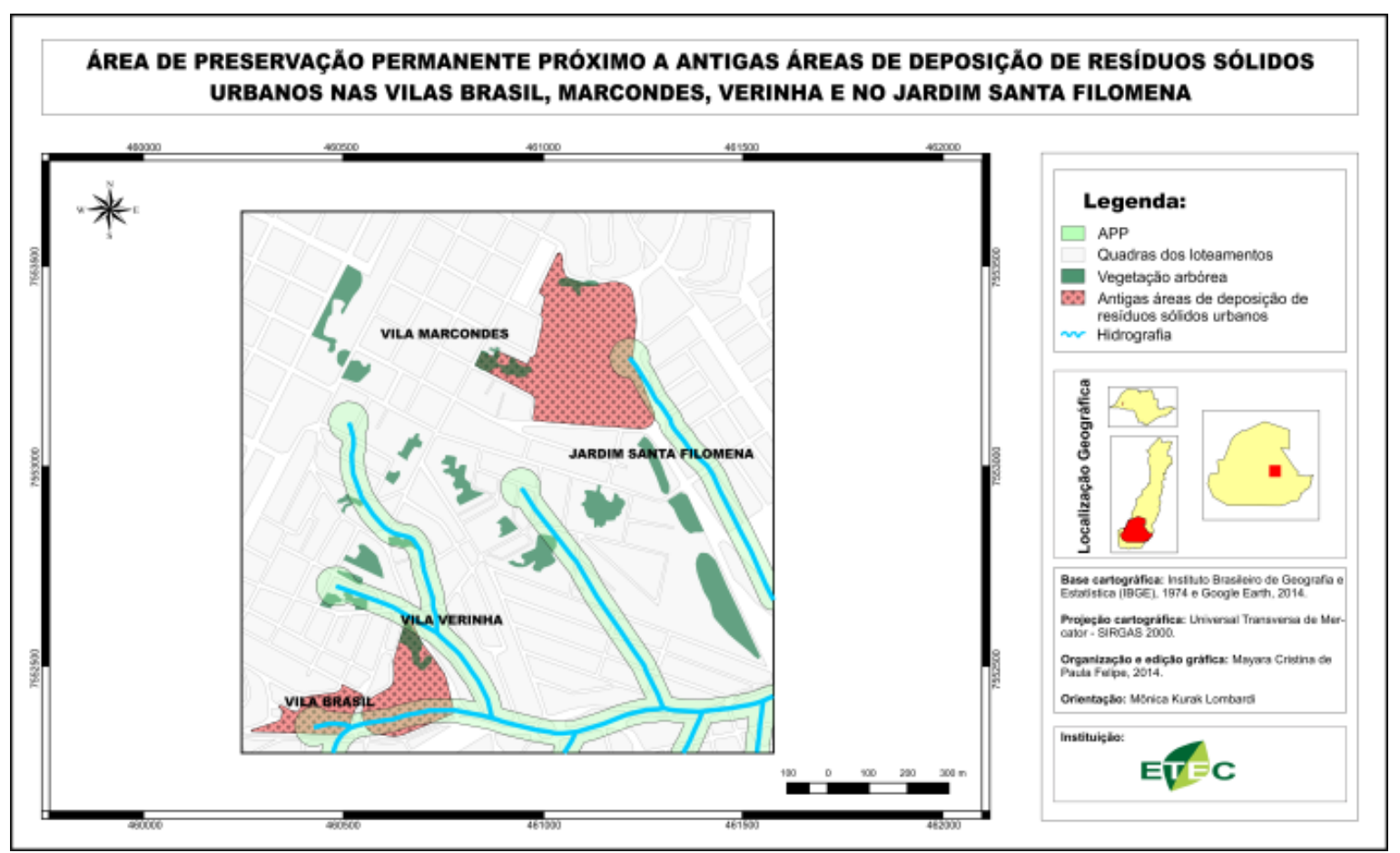

Figura 2. Localização de antigas áreas de deposição de resíduos sólidos urbanos nas Vilas Verinha, Marcondes, Brasil e no Jardim Santa Filomena, e sua aproximação com as APPs.

As antigas áreas de deposição de resíduos no Parque São Judas Tadeu (1975 e 1980), na Vila Geni (1976), no Parque Duque de Caxias (1979) e no Parque São Matheus (1982) também estavam localizadas em APP, como mostra a Figura 3.

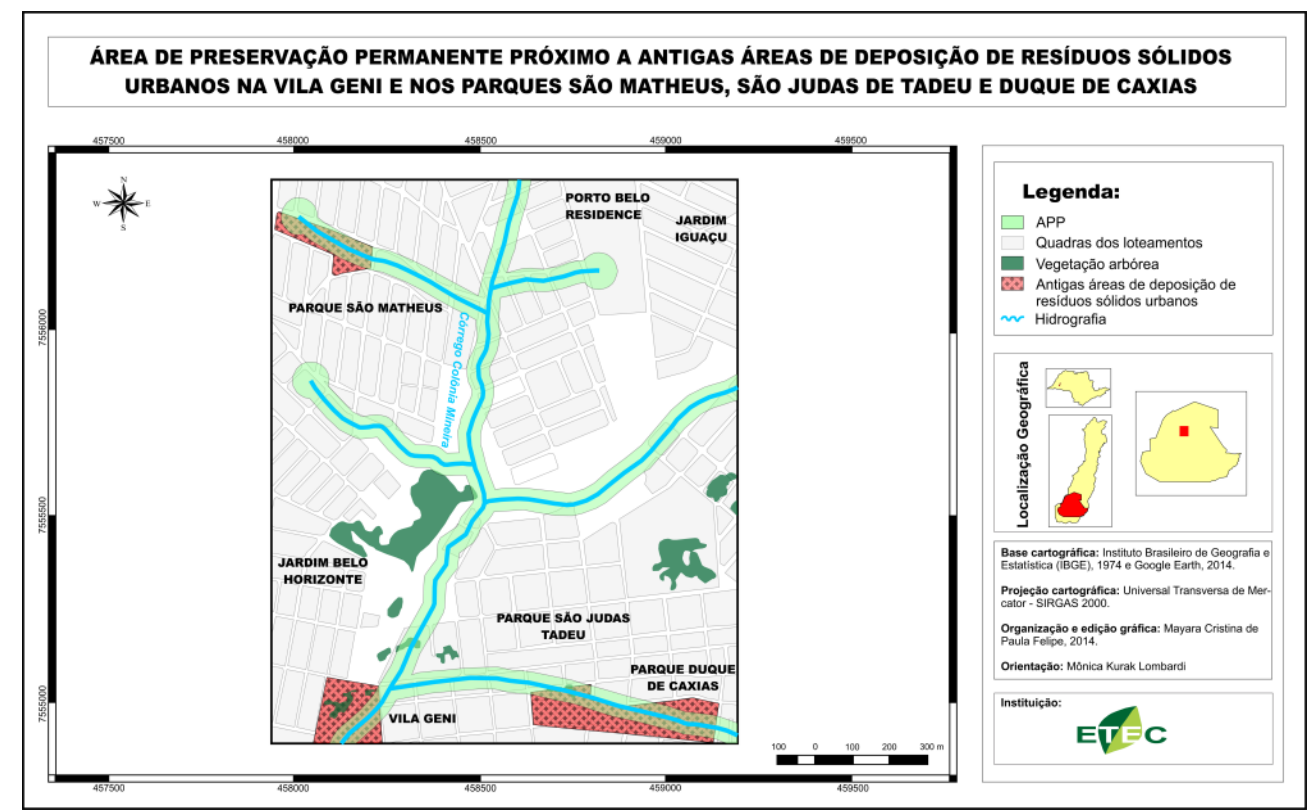

Figura 3. Localização de antigas áreas de deposição de resíduos sólidos urbanos na Vila Geni e nos Parques São Judas Tadeu, Duque de Caxias e São Matheus. 
As áreas de lixão no Jardim Planalto e na Vila Nova Prudente, além da atual área localizada no Distrito Industrial I "Antonio Crepaldi" possui muitos cursos d'água, assim, a partir da Figura 4 é possível perceber que os lixões estavam localizados em APP ou muito próximo dessas áreas como é o caso do lixão do Jardim Planalto. Em relação a atual área utilizada para a disposição dos resíduos sólidos urbanos, observa-se que a mesma encontra-se em APP.

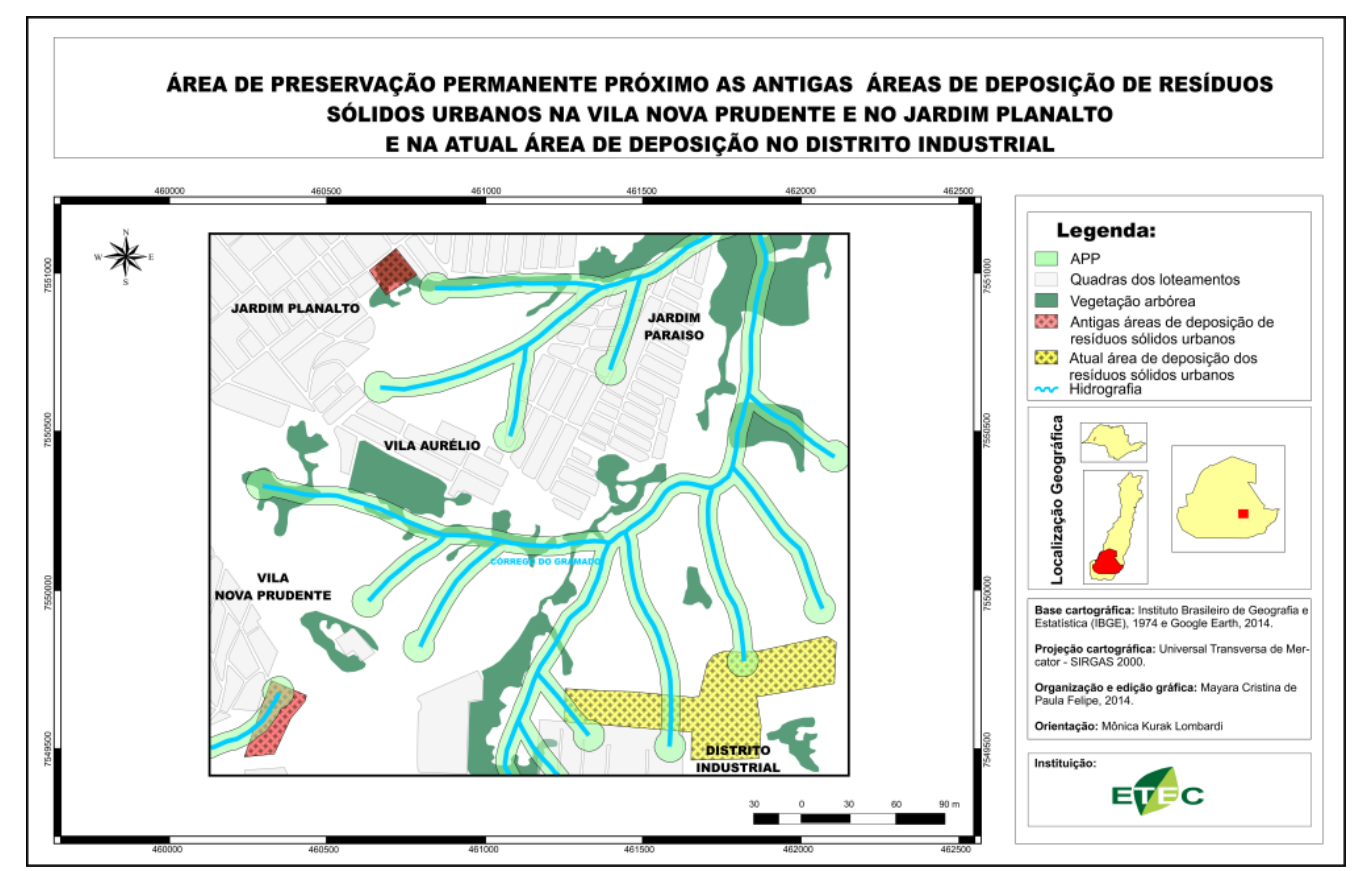

Figura 4: Localização de antigas áreas de deposição de resíduos sólidos urbanos na Vila Nova Prudente, no Jardim Planalto e no Distrito Industrial.

\section{DISCUSSÃO}

A partir dos casos estudados, observou-se que todas as áreas, que foram locais de deposição de resíduos sólidos urbanos, encontravam-se e encontram-se em APPs. Fato que gera muitos impactos negativos ao meio ambiente. Os resultados desse trabalho evidenciam a necessidade do município de Presidente Prudente ter um Aterro Sanitário para a deposição dos seus resíduos sólidos.

A atual área de disposição dos resíduos sólidos urbanos está com sua capacidade de utilização esgotada e em processo de encerramento. Embora tenha ocorrido a instalação de drenos para as águas superficiais e de chorume e o isolamento da área, esse local continua inadequado, em virtude da falta de impermeabilização e saída para uma estação de tratamento do chorume. 
No dia 18 de junho de 2008, foi protocolado um Termo de Ajustamento de Conduta (TAC), na Agência Ambiental Unificada, entre a Prefeitura e o Ministério Público do Estado (MPE). Dessa forma, como uma das medidas do TAC, no dia 14 de abril de 2010, os catadores foram retirados da área do lixão, tratando-se de uma medida para o encerramento definitivo dessa área (MARTIN; MAZZINI, 2010).

Segundo Lopes (2014), com o objetivo de atender as exigências para o fechamento do lixão municipal, a empresa Prudenco expandiu em 15\% a sua área de abrangência, correspondendo a $260 \mathrm{mil} \mathrm{m}^{2}$, pois, para o fechamento, deve-se realizar o aterro do lixo depositado atualmente, o plantio de grama e a retirada do chorume, o qual será levado à Estação de Tratamento de Esgoto (ETE) da Companhia de Saneamento Básico do Estado de São Paulo (SABESP). Ainda segundo informações de Lopes (2014), até o dia 09 de outubro de 2014, não foi consolidada a compra do terreno que abrigará a nova área do aterro sanitário da cidade, na zona norte. O prazo firmado no TAC para a construção do novo aterro é até 2015.

\section{CONCLUSÃO}

Conclui-se que ao longo de várias administrações municipais o manejo dos resíduos sólidos urbanos no município de Presidente Prudente apresentou graves problemas relacionados à sua disposição final, pois a grande maioria se localizava em Áreas de Preservação Permanente, não ocorrendo nenhuma análise ambiental.

Os resultados revelam que a administração municipal sempre buscou tirar o volume dos resíduos sólidos do campo de visão da população e, para isso os depositaram em áreas periféricas onde já existia uma população de baixo poder aquisitivo, sobretudo, nas zonas Leste e Norte.

Vale ressaltar, que esse trabalho possibilitou identificar antigas áreas de lixão na parte central da cidade, as quais atualmente não possuem nenhum resquício dessa atividade. Ao contrário do que ocorre em muitas das outras áreas, que se encontram em situação de abandono, sendo que em muitos casos a própria população continua a jogar resíduos nesses locais.

\section{REFERÊNCIAS}

BRASIL. Lei no 12.727, de outubro de 2012. Altera a Lei no 12.651, de 25 de maio de 2012, que dispõe sobre a proteção da vegetação nativa. Presidência da República Casa Civil subchefia para assuntos jurídicos, Brasília, 191 da Independência e 124ㅇ da República, p.1-10, out. 2012.

Resolução do CONAMA, no 302, de 20 de março de 2002. Disponível em: <http://www.mma.gov.br/port/conama/processos/61AA3835/LivroConama.pdf>. Acesso em: 10 de set. de 2014. 
CARRION, C. A.; KURAK, M. Lixo urbano e impactos sócio-ambientais em Presidente Prudente. 1996. 51 f. Trabalho de conclusão de curso (Graduação em Geografia) - Faculdade de Ciências e Tecnologia, Universidade Estadual Paulista, Presidente Prudente.

LOPES, R. Expansão integra processo de encerramento. O Imparcial, Presidente Prudente, 09 out. 2014. Prudente. Disponível em:< http://www.imparcial.com.br/site/expansao-integra-processode-encerramento>. Acesso em: 14 nov. 2014.

MARTIN, E. S. MAZZINI, E. J. T. Disposição final do lixo em Presidente Prudente: de 1923 a 2010. Rev. Tópos, Presidente Prudente, v. 4, n. 2, p.109-143. 2010.

MAZZINI, E. J. T. De lixo em lixo em Presidente Prudente (SP): Novas áreas, velhos problemas. Trabalho de conclusão de curso (Graduação em Geografia) - Faculdade de Ciências e Tecnologia, Universidade Estadual Paulista, Presidente Prudente, 1997. 96p.

TAKENAKA, E. M. Políticas públicas de gerenciamento integrado de resíduos sólidos urbanos no município de Presidente Prudente-SP. Tese (Pós-Graduação em Geografia) - Faculdade de Ciências e Tecnologia, Universidade Estadual Paulista. Presidente Prudente, 2008. 236 p. 